\title{
Venous infarction of the myocardium in a newborn child: An unusual effect of disseminated intravascular coagulation
}

\author{
M. McCORMACK \\ From the Department of Pathology, University of Aberdeen
}

SYNOPSIS A case is described of disseminated intravascular coagulation in a premature female infant, with the unusual and predominating feature of myocardial infarction consequent uponcoronary vein thrombosis.

Some reference is made to the incidence of coagulation disorders in the newborn and to methods of histological diagnosis.

Myocardial infarction is an unusual but well recognized phenomenon in infancy and childhood, and results from a variety of local or general disturbances (Stryker, 1946; Friedberg and Horn, 1939; Makous, Friedman, Yakovac, and Maris, 1962). In the majority of reported cases, there is either occlusive coronary artery disease, or a coronary artery (most commonly the left) has an abnormal origin and delivers venous blood. In a few cases ischaemic heart disease has occurred in association with severe anaemia.

There does not, however, appear to be any report of neonatal myocardial infarction following coronary vein occlusion, although theoretically such a syndrome might be expected to exist. Consequently, in view of its apparent rarity, a report of the following case seems warranted.

\section{Case Report}

The mother was a healthy 28-year-old woman who had had a previous breech stillbirth and two subsequent normal pregnancies which resulted in healthy infants.

Her fourth pregnancy had been uneventful till the sudden onset of labour at an estimated gestation of 38 weeks. Labour itself was uncomplicated and a premature female infant was born by spontaneous vertex delivery. The umbilical cord was wrapped tightly around the neck, and sustained respiration was not achieved till two minutes after delivery. In spite of continuous oxygen administration the child Received for publication 19 March 1973. was deeply cyanosed from birth. Because of this she was transferred to the special nursery at Aberdeen Maternity Hospital - a journey of approximately 60 miles-and arrived there at the age of 3 hours.

On examination she was grossly cyanotic and dyspnoeic, with a heart rate of $174 / \mathrm{min}$. The heart sounds were soft and there were no murmurs; the peripheral pulses were full. Widespread crepitations over both lungs were heard, and a firm liver edge could be palpated $4 \mathrm{~cm}$ below the costal margin. An ECG showed first degree atrioventricular block, with delayed intraventricular conduction. In the light of these findings, a diagnosis of aberrant left coronary artery was made.

Treatment consisted of oxygen, digoxin $0.14 \mathrm{mg}$, and frusemide $6 \mathrm{mg}$, but at the age of 11 hours the child died from cardiac arrest.

\section{Necropsy}

The subject was a premature female infant.

All the internal organs were normally situated, and macroscopic abnormalities were confined to the heart and meninges.

The heart weighed $21 \mathrm{~g}$. The coronary arteries arose, and were distributed, normally. Externally, the lateral wall of the left ventricle showed a dusky blue discolouration, and on section the myocardium in this region contained mottled areas of congestion and pallor, extending from the epicardial to the endocardial surfaces. Elsewhere, the myocardium was of normal appearance and the internal anatomy of the heart was normal, the right and left ventricular 


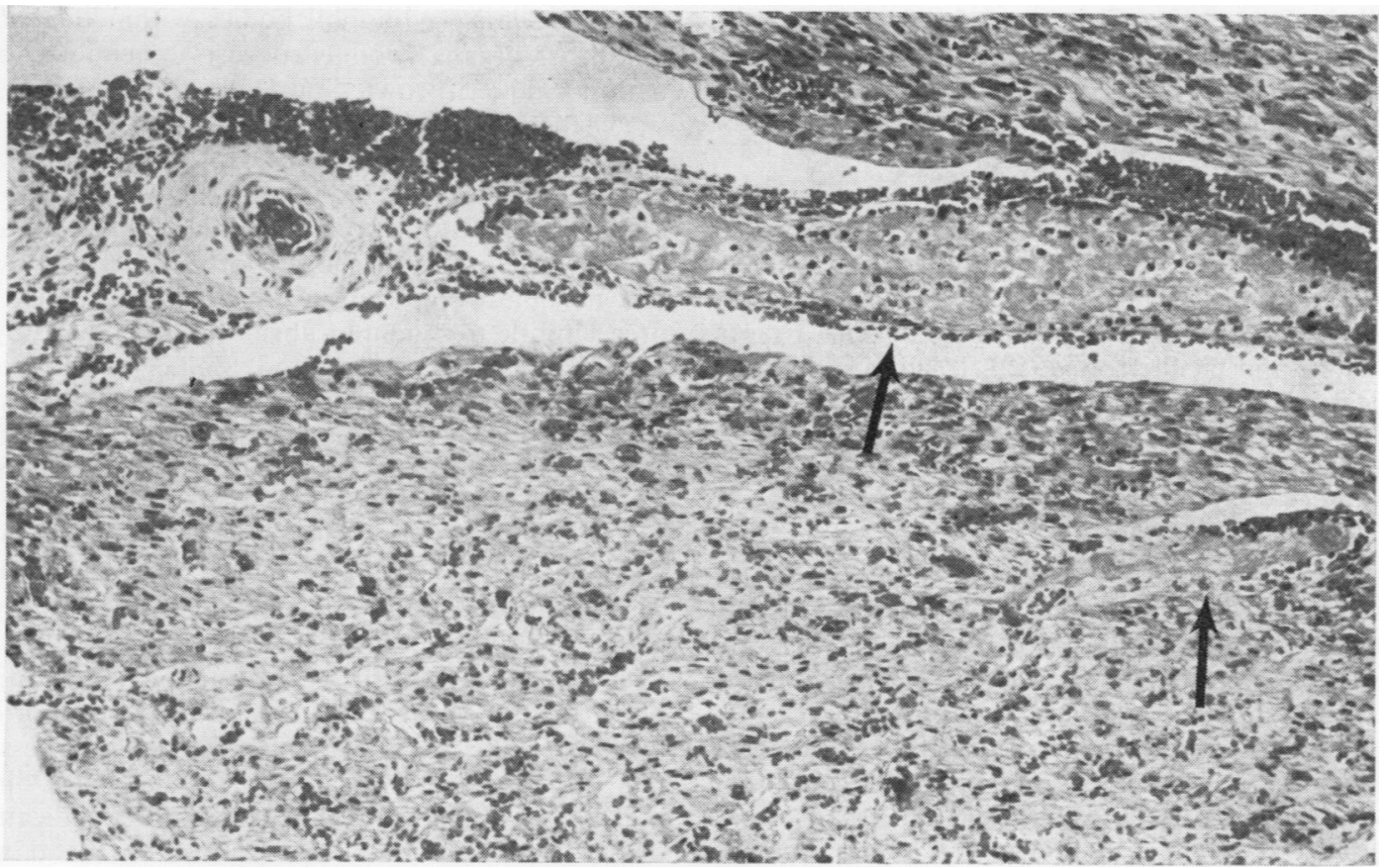

Fig 1 A large coronary vein (arrowed) containing antemortem thrombus with a few admixed white blood cells. Adjacent to it is a normal artery, and the myocardium is congested, necrotic, and focally haemorrhagic. A smaller thrombosed vein (below, right) is also indicated (haematoxylin and eosin; enlarged from magnification $\times 13.4$ ).

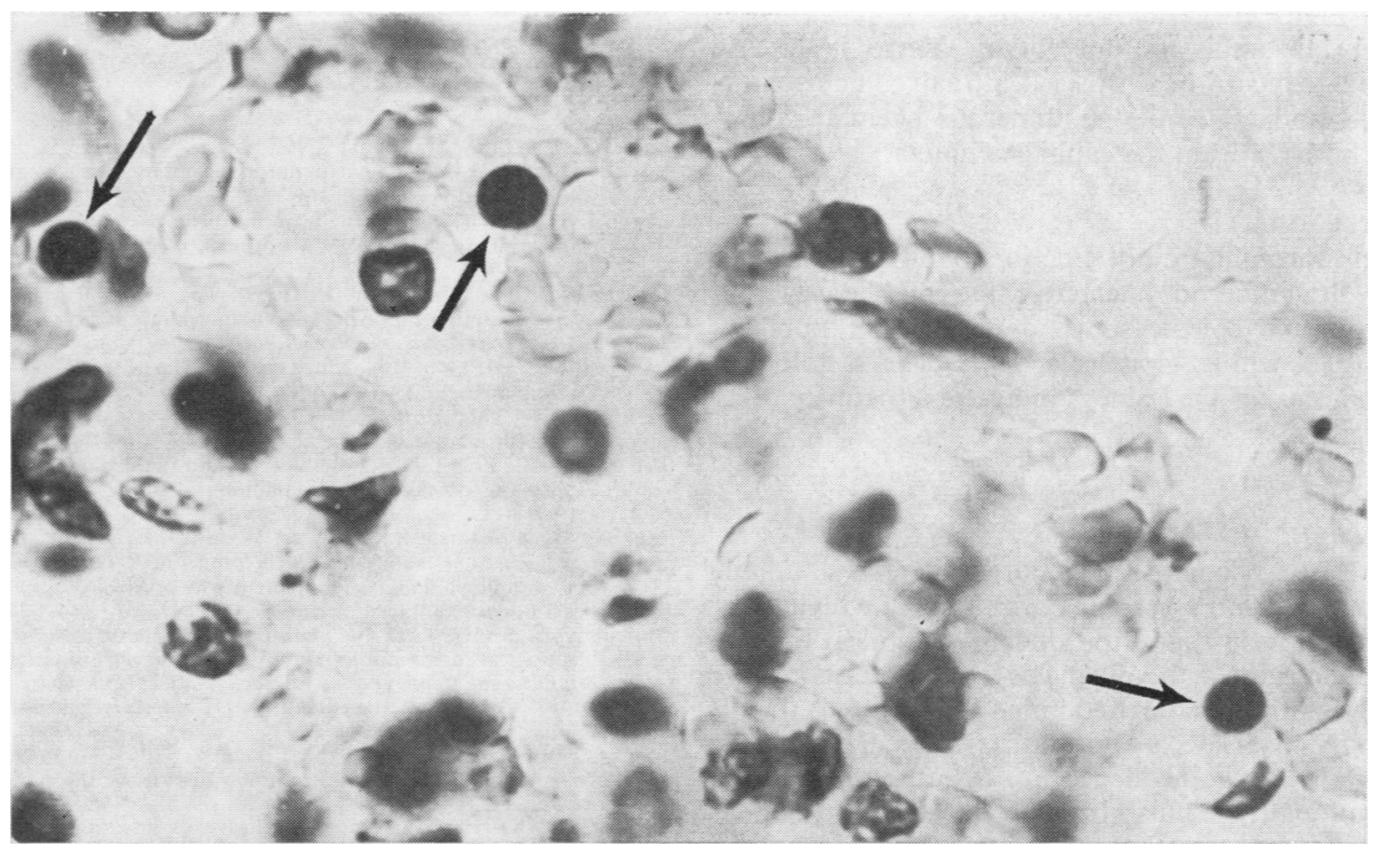

Fig 2 Lung capillaries containing three (arrowed) haematoxylinophil bodies (haematoxylin and eosin; oil immersion, enlarged from magnification $\times 400$ ). 
wall thickness being $7 \mathrm{~mm}$ and $5 \mathrm{~mm}$ respectively.

Although the brain was normal, there was some separation of the layers of the falx cerebri by a minor haemorrhage.

\section{Histology}

All sections were stained routinely with haematoxylin-eosin, and Lendrum's Martius Scarlet Blue stain for polymerized fibrin (Lendrum, Fraser, Slidders, and Henderson, 1962). In addition, several of the lung sections were stained with phosphotungstic acid-haematoxylin, and the von Kossa stain for calcium was used on several of the heart sections.

\section{HEART (FIG 1)}

There is a large area of necrosis with dissolution of fibres and only a thin rim of spared tissue at the epicardial and endocardial surfaces. The capillaries in this region show extreme congestion and there is focal rupture with extravasation of erythrocytes into the tissues. In several areas coronary veins containing fibrin thrombi are evident, and there are small numbers of platelets and leucocytes entrapped in this fibrin network.

The entire tissue block was serially sectioned, but in no area was coronary artery abnormality found.

\section{LUNG (FIG 2)}

Fibrin thrombi are not found. There is intense venous congestion with focal intraalveolar haemorrhage, and, in addition, numerous haematoxylinophil bodies within the capillary lumina.

\section{OTHER ORGANS}

Fibrin thrombi are not seen in any other organ, but there are numerous haematoxylinophil bodies within hepatic and splenic sinusoids, and lesser numbers identified within glomerular tufts. The histological appearance of the kidneys indicates a maturity of $\mathbf{3 6}$ weeks.

\section{Discussion}

This case demonstrates an apparently unique example of intravascular coagulation involving the coronary veins, and producing a clinical picture which suggested the diagnosis of aberrant coronary artery. Although the predominating feature is that of coronary vein occlusion and its immediate effects, there is ample evidence of a more generalized coagulopathy. Thus, although fibrin is not demonstrated in organs other than the heart, the identifica-

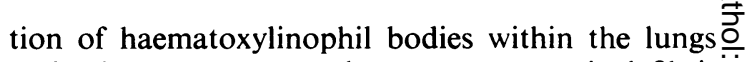
and other organs strongly suggests systemic defibri- $\overrightarrow{\overrightarrow{\vec{A}}}$ nation (Stalker, Brown, and Hall, 1969).

The aetiology of such intravascular disasters is considered to be the release of placental thromboplastin into the foetal circulation (Stark, Abramson, $\frac{\bar{\sigma}}{\sigma}$ and Erkan, 1968) and premature infants are especially $\cong$ at risk. Such an event need not be attended by a recognizable complication of pregnancy such as $\vec{O}$

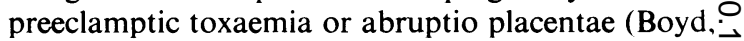
1965, 1967), and Brown and Stalker (1969) have $\vec{\omega}$ shown that it consistently occurs in the hamster during labour and placental separation, and also when the foetus first draws breath, provided that the umbilical cord remains unclamped.

The incidence of disseminated intravascularid coagulation as a significant factor in deaths within $\rightarrow$ $48 \mathrm{hr}$ of birth has been estimated at $3.5 \%$ (Boyd, 음 1967). The single criterion for arriving at thisfigure, however, was the postmortem demonstration? of fibrin thrombi. Because of pre- and postmortem $<$ fibrinolysis the actual figure may be well in excess of $\overrightarrow{0}$ this. Recognizing the presence of haematoxylino-cे phil bodies should give a more accurate indication of the contribution of this process to foetal and? infant loss.

The author wishes to thank Dr N. S. Clark for permission to report this case, and Professor A. L.⿳亠丷厂二 Stalker for advice and guidance.

\section{References}

Boyd, J. F. (1965). Disseminated fibrin thrombo-embolism among stillbirths and neonatal deaths. J. Path. Bact., 90, 53-63.

Boyd, J. F. (1967). Disseminated fibrin thromboembolism among. neonates dying within 48 hours of birth. Arch. Dis. Childh., $42 \overbrace{}^{\circ}$ $401-409$.

Brown, L. J., and Stalker, A. L. (1969). The maternal and foeta microcirculation following placental separation or trauma. Ito 5th European Conference on Microcirculation, Gothenburg, 1968 (Bibl. anat., No. 10), edited bv H. Harders, pp. 374-378D Karger, Basle, and New York.

Friedberg, C. K., and Horn, H. (1939). Acute myocardial infarction noFdue to coronary occlusion. J. Amer. med. Ass., 112, 1675-1679 N

Lendrum, A. C., Fraser, D. S., Slidders, W., and Henderson, R. (1962) Studies on the character and staining of fibrin. J. clin. Path.N 15, 401-413.

Makous, N., Friedman, S., Yakovac, W., and Maris, E. P. (1962) טు Cardiovascular manifestations in progeria. Report of clinica $b$ and pathologic findings in a patient with severe arteriosclerotik heart disease and aortic stenosis. Amer. Heart J., 64, 334-3460

Stalker, A. L., Brown, L. J., and Hall, J. (1969). Microcirculatory an $\frac{1}{\Phi}$ histological observations on experimental defibrination. In 5th European Conference on Microcirculation, Gothenburg, $1968^{+}$ (Bibl. anat., No. 10), edited by H. Harders, pp. 366-373.0 Karger, Basle, New York.

Stark, C. R., Abramson, D., and Erkan, V. (1968). Intravascula $\frac{O}{\not}$ coagulation and hyaline-membrane disease of the newborn Lancet, 1, 1180-1181.

Stryker, W. A. (1946). Coronary occlusive disease in infants an in children. Amer. J. Dis. Childh., 71, 280-300. 